\title{
The Pathogenic Effect of Cortactin Tyrosine Phosphorylation in Cutaneous Squamous Cell Carcinoma
}

\author{
LIANHUA ZHU ${ }^{1 *}$, EUNAE CHO ${ }^{2 *}$, GUOHUA ZHAO ${ }^{1}$, MI RYUNG ROH ${ }^{3}$ and ZHENLONG ZHENG ${ }^{1,4}$ \\ ${ }^{1}$ Department of Dermatology, Yanbian University Hospital, Yanji, P.R. China; \\ ${ }^{2}$ Department of Oral Pathology, Oral Cancer Research Institute, \\ Yonsei University College of Dentistry, Seoul, Republic of Korea; \\ ${ }^{3}$ Department of Dermatology, Severance Hospital, Seoul, Republic of Korea; \\ ${ }^{4}$ Department of Dermatology, International St. Mary's Hospital, Catholic Kwandong University, \\ College of Medicine, Incheon, Republic of Korea
}

\begin{abstract}
Background/Aim: Cortactin (CTTN) has been considered a promising molecular prognostic factor in various types of cancers. In this study, we aimed to investigate the role of CTTN in the pathogenesis of cutaneous squamous cell carcinoma (CSCC). Materials and Methods: CTTN and phospho-CTTN (p-CTTN) expression was determined in 10 healthy controls and 38 CSCC tissue samples by immunohistochemistry. The influence of CTTN on the biological behavior of CSCC cells was also investigated. Results: $p$-CTTN expression was significantly increased in CSCC than control samples. In contrast, no significant difference in CTTN expression was found between control and CSCC tissues. Moreover, a significant association was found between recurrence-free survival with p-CTTN expression, but not with CTTN expression. Furthermore, the proliferative, migratory, and invasive abilities of CSCC cells were significantly decreased by CTTN-siRNA transfection. Conclusion: CTTN phosphorylation is strongly associated with CSCC pathogenesis and may serve as a molecular biomarker of CSCC.
\end{abstract}

This article is freely accessible online.

*These two Authors contributed equally to this work.

Correspondence to: Zhenlong Zheng, Department of Dermatology, Yanbian University Hospital, No. 1327, Juzi Road, Yanji City, 133000, P. R. China. Tel: +86 4332660121, Fax: +86 4332513610, e-mail: hao1031@yuhs.ac; Mi Ryung Roh, Department of Dermatology, Yonsei University College of Medicine, Gangnam Severance Hospital, 211 Eonju-ro, Gangnam-gu, Seoul 135-720, Republic of Korea. Tel: +82 220193363, Fax: +82 23939157, e-mail: karenroh@yuhs.ac

Key Words: Cortactin, phosphorylation, oncogenic effect, cutaneous squamous cell carcinoma, molecular biomarker.
Cutaneous squamous cell carcinoma (CSCC) is the second most common keratinocyte carcinoma (1). Although CSCC has a relatively low recurrence and metastasis rate (2), its incidence is rapidly increasing (3). As the molecular pathogenesis of CSCC is heavily influenced by UV radiation-induced mutagenesis, investigation into the molecular basis of CSCC can provide more reliable diagnostic biomarkers, as well as therapeutic targets.

The Src family tyrosine kinases are known to be involved in integrin-mediated biological processes including cell proliferation, actin organization, and cell migration (4-9). Some investigators have demonstrated that Src is frequently hyperactivated in various types of cancers, particularly in metastatic lesions $(6,10,11)$. The critical roles of Src family kinases are thought to be largely dependent on their substrates, and cortactin is known as a direct substrate of cellular Src kinase (12).

As an actin binding protein, cortactin (CTTN) is encoded by the CTTN gene, located at chromosome 11q13 and enriched in the lamellipodia and membrane ruffles of cells; it regulates actin dynamics and is known to be associated with cell motility in vitro $(13,14)$. Overexpression and amplification of CTTN are frequently detected in various types of cancers and are considered a promising indicator of poor prognosis (15-26). More recently, many researchers have analyzed post-translational modifications of CTTN (16, 17, 27). Moreover, studies have demonstrated that tyrosine phosphorylation of CTTN is mediated by various tyrosine kinases such as $\operatorname{Src}(28,29)$.

Src can phosphorylate CTTN at the sites of three tyrosine residues Tyr421, Tyr466, and Tyr482 in vitro (30). Srcmediated CTTN phosphorylation has been reported to be involved in the integrin-induced cell spreading and adhesion process (31). Compared to CTTN, which is colocalized in lamellipodia with Src and actin, tyrosine phosphorylated CTTN (p-CTTN) is located at focal adhesions, especially at 
the ends of F-actin stress fibers, all three tyrosine residues Tyr421, Tyr466, and Tyr482 of CTTN are being phosphorylated upon focal adhesion $(32,33)$. Phosphorylation of Tyr421, Tyr466, and Tyr482 of CTTN has frequently been observed in vitro in many types of cells including cancer cells, and is a critical factor in cell migration $(29,30,34,35)$. In gastric cancer cell lines, decreased cell motility induced by CTTN knockdown was restored by wild-type CTTN overexpression, but not by $C T T N$ mutated in tyrosine residues such as Tyr421, Tyr466, and Tyr482 (36). Similar results have also been reported in breast cancer cell lines (37). Moreover, after transfecting mutant CTTN (Tyr 421/466/482), endothelial cells presented decreased cell motility in vitro (38). In spite of several in vitro studies demonstrating the critical role of p-CTTN in the motility of several cell types, little is known regarding the clinicopathological implications of p-CTTN in cancer patients.

In this study, we investigated the influence of CTTN expression on the biological behavior of CSCC cell lines, for the first time, as well as the clinicopathological significance of both CTTN and p-CTTN in a cohort of CSCC patients.

\section{Materials and Methods}

Clinical materials. In total, 10 normal skin and 38 CSCC tissue specimens were included in this study. All specimens were obtained from the Department of Pathology, Yonsei University Health System in Seoul, Korea. The clinicopathological characteristics of the patients are summarized in Table I. This study was approved by the Institutional Review Board for Bioethics of Yonsei University Health System, Severance Hospital (IRB 2018-0874-001).

Immunochemical staining. For immunohistochemistry, the tissue sections were deparaffinized with xylene and hydrated using a graded ethanol. After antigen retrieval and blocking of endogenous peroxidase activity, the sections were incubated with primary antibody at RT for $1 \mathrm{~h}$. Each group of cells was seeded in a chamber slide (Thermo Fisher Scientific, Waltham, MA, USA) at a density of $2 \times 10^{4}$. After $24 \mathrm{~h}$ of culture, the cells were fixed with $95 \%$ ethanol for $30 \mathrm{~min}$ at RT, and then incubated with primary antibody at RT for $1 \mathrm{~h}$. Cortactin (Abcam, Cambridge, MA, USA), pTyr421CTTN (LifeSpan BioSciences, Seattle, WA, USA) and p Try466CTTN (LifeSpan BioSciences) were used in this study, and REAL EnVision HRP Rabbit/Mouse Detection System (Dako, Santa Clara, CA, USA) was used as secondary antibody. Visualization was performed using the chromogen 3,3'-diaminobenzidine and counterstaining was performed with hematoxylin. Rabbit IgG (DakoCytomation Denmark A/S, Glostrup, Denmark) was used as a negative control.

As described in a previous study, the weighted histoscore method was used to score each protein expression according to staining intensity and the percentage of positive cells (39). The tumour cell intensity was scored as 0 (negative), 1 (light brown), 2 (brown), and 3 (dark brown). The histoscore was calculated as follows: Total score $=(0 \times$ percentage of negative cells $)+(1 \times$ percentage of lightbrown cells $)+(2 \times$ percentage of brown cells $)+(3 \times$ percentage of dark-brown cells). Based on the total histoscore, the samples were further divided into two expression groups, low (histoscores 0 through 100) and high (histoscores 101 through 300).

Cell lines and culture. Human CSCC cells (HSC-1 and HSC-5) were obtained from the Japanese Collection of Research Bioresources (Osaka, Japan) for use in this study. These cell lines were cultured in Roswell Park Memorial Institute 1640 medium (Nissui Pharmaceutical Co., Ltd., Tokyo, Japan) supplemented with $10 \%$ foetal bovine serum (Invitrogen, Carlsbad, CA, USA), $100 \mathrm{U} / \mathrm{ml}$ penicillin, and $0.1 \mathrm{mg} / \mathrm{ml}$ streptomycin-amphotericin B (Lonza, Basel, Switzerland), at $37^{\circ} \mathrm{C}$ under a humidified $5 \% \mathrm{CO}_{2}$ atmosphere. CTTN knockdown in these cells was performed by short-interfering RNA (siRNA) transfection ( $s i C T T N$; invitrogen) using Lipofectamin 2000 (Invitrogen) according to the manufacturer's protocol. A scrambled (Scr)-siRNA (Bioneer, Korea) was used as negative control. Knockdown efficiency was determined by reversetranscription real-time quantitative polymerase chain reaction (RTqPCR) and immunochemical staining.

$R T-q P C R$. Total RNA was isolated from HSC- 1 and HSC- 5 cells after transfection with CTTN-siRNA or Scr-siRNA using TRIzol Reagent (Invitrogen) according to the manufacturer's protocol. CTTN, marker of proliferation Ki-67 (MKI67), and proliferating cell nuclear antigen $(P C N A)$ mRNA expression was investigated following complementary DNA synthesis by qPCR analysis using $2 \times$ SYBR Premix Ex Taq II (Tli RnaseH Plus) (RR82LR; Takara, Ann Arbor, MI, USA) on an Applied Biosystems (Foster City, CA, USA) instrument. The following primers were used: MKI67 forward: 5'CCCCCACCAGAACTAACAGA-3' and reverse: 5'-ACTTTGAT GCCCTCATCACC-3'; PCNA forward: 5'-GAAGCACCAAACCA GGAGAA-3' and reverse: 5'-TCACTCCGTCTTTTGCACAG-3'; $\beta$ actin forward: 5'-ATAGCACAGCCTGGATAGCAACGTAC-3' and reverse: 5'-CACCTTCTACAATGAGCTGCGTGTG-3'. The relative expression of each gene was normalized with $\beta$-actin mRNA expression.

The influences of CTTN knockdown on the biological behaviour of the CSCC cells. To investigate the influence of CTTN expression on the biological behaviour of the cells, trypan blue assay, migration assay, and matrigel invasion assay were performed in HSC-1 and HSC-5 cells after transfection with $C T T N$-siRNA or Scr-siRNA. For trypan blue assay, those cells were seeded in a 6-well plate at a density of $1 \times 10^{4}$ and counted each day for 3 days after trypan blue staining. For wound-healing assay, each group of cells were seeded in a 24 -well plate at a density of $3 \times 10^{4}$. At $90 \%$ confluency a scratch wound was made, whose relative closure was investigated after $24 \mathrm{~h}$. For matrigel invasion assay, each group of cells was seeded in a Matrigel-(BD Biosciences, San Jose, CA, USA) coated upper chamber of a transwell (BD Biosciences, Bedford, MA, USA) at a density of $5 \times 10^{4}$ with culture medium containing $1 \%$ FBS. Culture medium containing 10\% FBS was added in the bottom chamber. After $30 \mathrm{~h}$ of culture, invading cells were stained with $0.25 \%$ crystal violet and counted under the microscope.

Statistical analysis. The association between CTTN protein expression and clinicopathological variables of CSCC patients was analyzed with Fisher's exact test. Mann-Whitney $U$-test was used to examine the influences of CTTN knockdown on the biological behavior of the CSCC cells. Differences were considered to be statistically significant when $p<0.05$. 
Table I. Clinicopathological variables of the tissue samples.

\begin{tabular}{|c|c|}
\hline \multicolumn{2}{|l|}{ Clinicopathological variables } \\
\hline \multicolumn{2}{|l|}{ Normal skin tissues } \\
\hline Total no. of cases & 10 \\
\hline \multicolumn{2}{|l|}{ Age } \\
\hline Median age (range) & $62(42-87)$ \\
\hline \multicolumn{2}{|l|}{ Gender, $\mathrm{n}(\%)$} \\
\hline Male & $5(50)$ \\
\hline Female & $5(50)$ \\
\hline \multicolumn{2}{|l|}{ Site, n (\%) } \\
\hline Scalp & $2(20)$ \\
\hline Face & $4(40)$ \\
\hline Ear & $2(20)$ \\
\hline Acral & $2(20)$ \\
\hline \multicolumn{2}{|l|}{ CSCC } \\
\hline Total no. of cases & 38 \\
\hline \multicolumn{2}{|l|}{ Age } \\
\hline Median age (range) & $69(42-89)$ \\
\hline \multicolumn{2}{|l|}{ Gender, n $(\%)$} \\
\hline Male & $19(50)$ \\
\hline Female & $19(50)$ \\
\hline \multicolumn{2}{|l|}{ Site, $\mathrm{n}(\%)$} \\
\hline Scalp & $6(15.8)$ \\
\hline Face & $17(44.7)$ \\
\hline Ear & $5(13.2)$ \\
\hline Lip & $4(10.5)$ \\
\hline Acral & $6(15.8)$ \\
\hline \multicolumn{2}{|l|}{ Size, $\mathrm{cm}$} \\
\hline Median size (range) & $2.0(0.5-4.5)$ \\
\hline \multicolumn{2}{|l|}{ Differentiation } \\
\hline Well & $20(52.6)$ \\
\hline Moderate & $14(36.8)$ \\
\hline Poorly & $4(10.5)$ \\
\hline \multicolumn{2}{|l|}{ Recurrence } \\
\hline Yes & $18(47.4)$ \\
\hline No & $20(52.6)$ \\
\hline \multicolumn{2}{|l|}{ Duration of follow-up } \\
\hline Median (range, months) & $21.7(1.0-110.5)$ \\
\hline \multicolumn{2}{|l|}{ Interval of recurrence } \\
\hline Median (range, months) & $11.0(1.0-91.0)$ \\
\hline
\end{tabular}

\section{Results}

CTTN, pTyr421-CTTN, and pTry466-CTTN expression in normal skin and CSCC tissue samples. Representative expression patterns of CTTN, pTyr421-CTTN, and pTry466CTTN in the tissue samples are shown in Figure 1. Cytoplasmic expression of CTTN, pTyr421-CTTN, and pTry466-CTTN was frequently found in normal epithelial cells and cancer cells in tissue specimens. No significant difference was found between normal skin and CSCC samples in CTTN protein expression. High-CTTN expression was found in 7 $(70 \%)$ and $26(68.4 \%)$ of the normal skin and CSCC tissue samples, respectively (Figure 2A). In contrast, the frequency of both high-pTyr421-CTTN and high-pTry466-CTTN expression was significantly increased in CSCC tissues relative to normal skin tissue samples ( $p=0.003$, and $p=0.008$, respectively). High-pTyr421-CTTN and high-pTry466-CTTN expression was found in $21(47.4 \%)$ and 18 (55.3\%) CSCC tissue samples, respectively. However, no normal skin tissue samples exhibited high immunoreactivity for either pTyr421CTTN or high-pTyr466-CTTN (Figure 2A).

The clinicopathological significance of the expression of all three proteins in the 38 patients with CSCC was further investigated. None of the baseline clinicopathological parameters, including age, gender, site, tumor size, and differentiation of involvement, were significantly associated with tissue CTTN, pTyr421-CTTN, or pTyr466-CTTN expression in patients with CSCC (Table II). Meanwhile, Kaplan-Meier analysis showed that both pTyr421-CTTN and pTry466-CTTN expression were significantly correlated with recurrence-free survival of patients with CSCC. As a result, patients with high expression of pTyr421-CTTN (median survival duration of 29 months in the low expression group versus 13.7 months in the high expression group; $p=0.014$ ) or pTry466-CTTN (median survival duration of 47.4 months in low expression group versus 12.0 months in high expression group; $p=0.006$ ) exhibited poor recurrence-free survival rates (Figure 2B).

Efficient CTTN knockdown by siRNA transfection of human CSCC cancer cell lines. CTTN knockdown in CSCC cell lines was performed by siRNA transfection. Compared to Scr-siRNA control, CTTN mRNA expression in HSC-1 cells transfected with $C T T N$-siRNA was significantly decreased at $24 \mathrm{~h}$ $(0.24 \pm 0.04)(p<0.001), 36 \mathrm{~h}(0.22 \pm 0.05)(p<0.001)$, and $72 \mathrm{~h}$ $(0.44 \pm 0.01)(p<0.001)$ post siRNA transfection. $C T T N$-siRNAtransfected HSC-5 cells also showed significantly reduced CTTN mRNA expression at $24 \mathrm{~h}(0.30 \pm 0.04)(p<0.001), 36 \mathrm{~h}$ $(0.26 \pm 0.03)(p<0.001)$, and $72 \mathrm{~h}(0.41 \pm 0.02)(p<0.001)$ after transfection, compared to the related Scr-siRNA group. CTTN, pTyr421-CTTN, and pTry466-CTTN expression also prominently decreased in the $C T T N$-siRNA group relative to the Scr-siRNA group in both HSC-1 and HSC-5 cells (Figure 3A).

CTTN knockdown attenuated CSCC cells proliferation. Compared to Scr-siRNA control, the number of HSC-1 cells transfected with CTTN-siRNA was significantly decreased after siRNA transfection at $24 \mathrm{~h}(0.64 \pm 0.08)(p<0.001), 36 \mathrm{~h}$ $(0.42 \pm 0.06)(p<0.001)$, and $72 \mathrm{~h}(0.44 \pm 0.03)(p<0.001)$. HSC5 cells yielded similar results: $C T T N$-siRNA-transfected HSC5 cells showed a significantly reduced number of the cells at $24 \mathrm{~h}(0.80 \pm 0.05)(p<0.001), 36 \mathrm{~h}(0.56 \pm 0.06)(p<0.001)$, and $72 \mathrm{~h}(0.31 \pm 0.03)(p<0.001)$ after transfection compared to the related Scr-siRNA group. Moreover, compared to the ScrsiRNA control, significantly decreased MKI67 (both $p<0.001$ ) and PCNA (both $p<0.001$ ) mRNA expression were found in both HSC-1 and HSC-5 cell lines at $24 \mathrm{~h}$ after CTTN siRNA transfection (Figure 3B). 

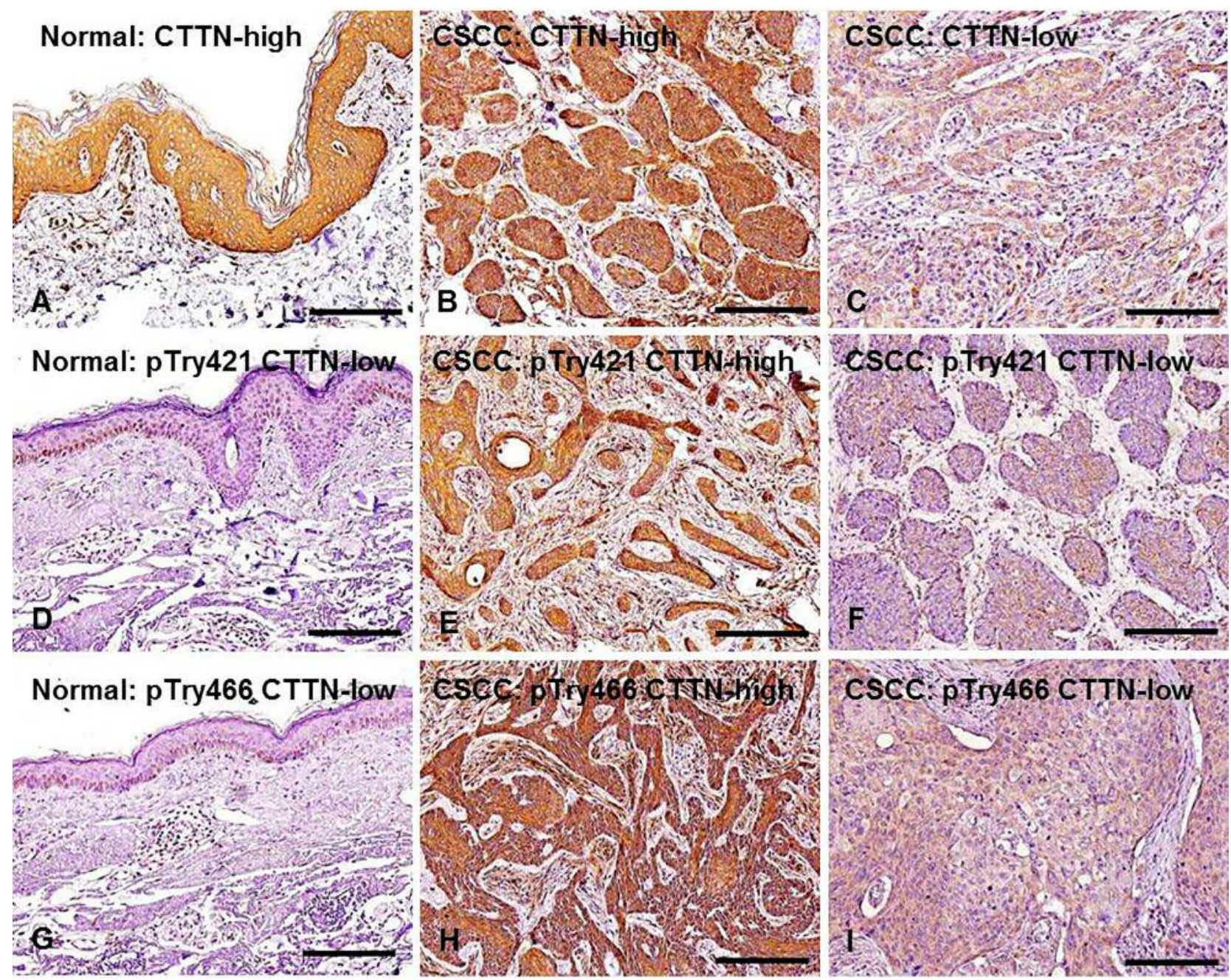

Figure 1. Representative expression patterns for CTTN, pTry421-, and pTry466-CTTN expression in normal skin ( $A, D, G)$ and CSCC tissue samples $(B, C, E, F, H, I)$. Cytoplasmic expression of CTTN was found in both normal skin and CSCC tissue samples. Original magnification: $\times 200 ;$ scale bar $=200 \mu \mathrm{m}$.

CTTN knockdown attenuated CSCC cell migration and invasion. The effect of CTTN on CSCC cell migration was investigated using a wound-healing assay. Compared to the related ScrsiRNA control, transfection of CTTN-siRNA significantly reduced the migration ability of both HSC-1 and HSC-5 cells as measured at $24 \mathrm{~h}$ after scratch wounding (Figure 3C). In addition, the influence of CTTN on the invasion ability of CSCC cells was investigated by a matrigel invasion assay. The number of CTTN-siRNA transfected HSC-1 and HSC-5 cells having traversed the membrane was found to be significantly decreased (both $p<0.001$ ) compared to the Scr-control (Figure 3C).

\section{Discussion}

Despite ongoing efforts to identify the role of CTTN in tumorigenesis of various types of cancers, it has not been investigated in CSCC. In this study, the influence of CTTN knockdown on the proliferation, migration, and invasion abilities of CSCC cell lines was investigated. Similar to other cancers, CTTN knockdown significantly attenuated both the migration and invasion ability of CSCC cells $(21,22)$. Moreover, the proliferation ability of CSCC cell lines was also decreased after CTTN knockdown. These data suggest that cortactin may play a critical role in CSCC progression.

Clinicopathological implications of CTTN overexpression have been investigated in various types of cancers, such as head and neck, colorectal, gastric cancers, renal cell carcinoma, breast cancers, and osteosarcoma. Studies have demonstrated that CTTN overexpression is significantly associated with various indicators of poor prognosis including higher $\mathrm{T}$ stage, lymph node metastasis, increased recurrence rates and decreased overall survival in cancer patients $(18-23,40,41)$. 
A

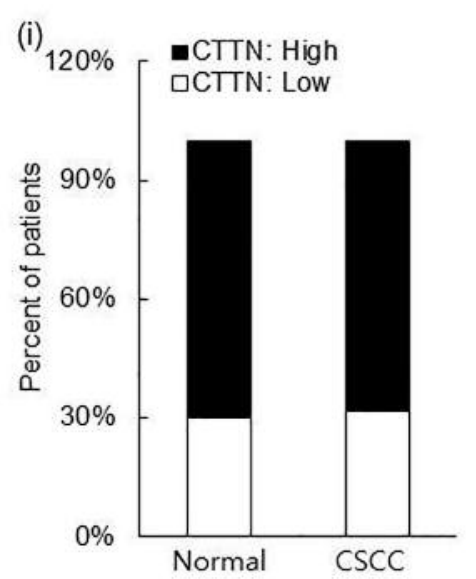

B (i)

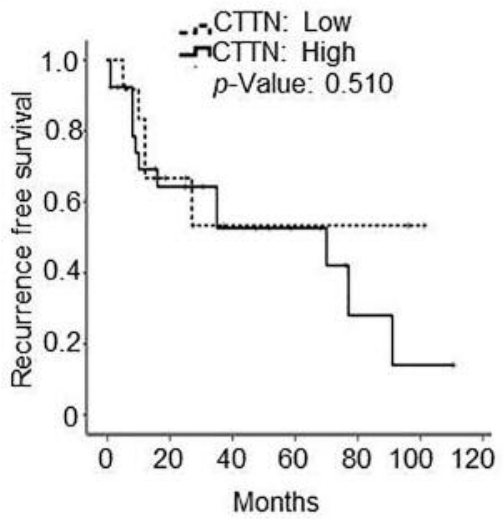

(ii)

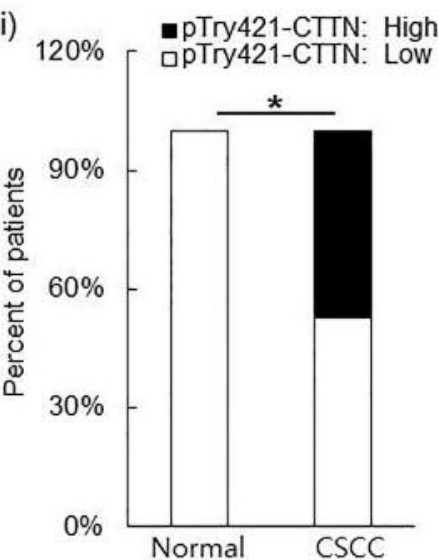

(ii)

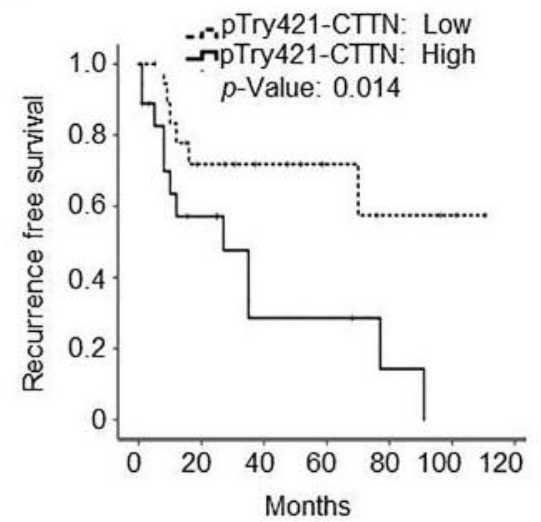

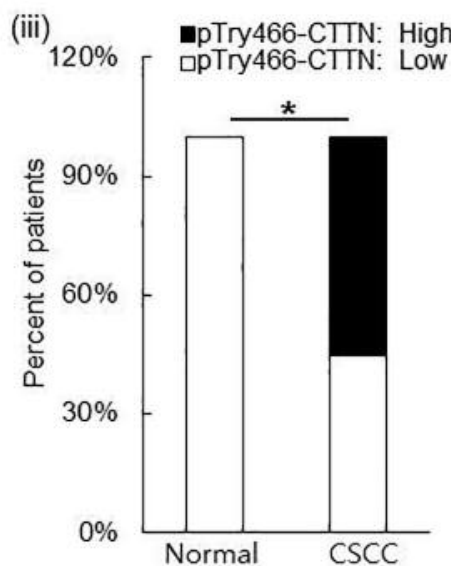

(iii)

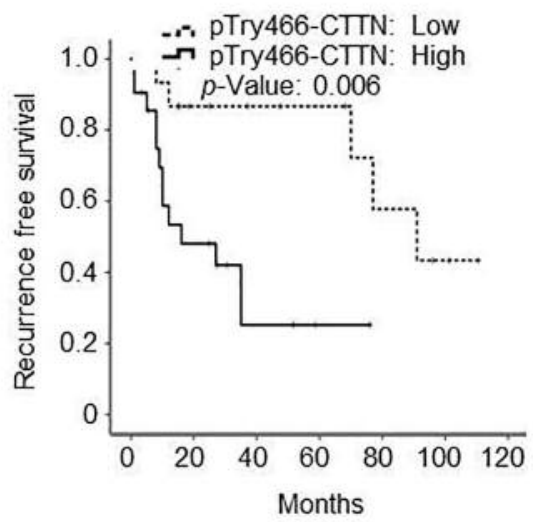

Figure 2. Clinicopathological associations of CTTN, pTry421-, and pTry466-CTTN expression in surgical samples. A: Significant difference was found between normal skin and CSCC tissue samples in pTry421- and pTry466-CTTN expression, but not in CTTN expression (i-iii) (*p<0.05). B: In CSCC patients, both pTry421-, and pTry466-CTTN expression showed a significant association with recurrence-free survival (ii and iii), but CTTN expression did not $(i)(* p<0.05)$.

Table II. Clinicopathological significance of CTTN, pTry421-CTTN, and pTry466-CTTN expression in 38 CSCC patients.

\begin{tabular}{|c|c|c|c|c|c|c|c|c|c|c|c|}
\hline \multirow[b]{2}{*}{ Variable } & & \multirow[b]{2}{*}{ No. of cases, $(\%)$} & \multicolumn{2}{|c|}{ CTTN } & \multirow[b]{2}{*}{$p$-Value } & \multicolumn{2}{|c|}{ pTry421-CTTN } & \multirow[b]{2}{*}{$p$-Value } & \multicolumn{2}{|c|}{ pTry466-CTTN } & \multirow[b]{2}{*}{$p$-Value } \\
\hline & & & Low & High & & Low & High & & Low & High & \\
\hline \multirow[t]{2}{*}{ Age } & $<69$ years & $19(50)$ & $3(15.8)$ & $16(84.2)$ & \multirow[t]{2}{*}{0.079} & $12(63.2)$ & $7(36.8)$ & \multirow[t]{2}{*}{0.33} & $8(42.1)$ & $11(57.9)$ & 1 \\
\hline & $\geq 69$ years & $19(50)$ & $9(47.4)$ & $10(52.6)$ & & $8(42.1)$ & $11(57.9)$ & & $9(47.4)$ & $10(52.6)$ & \\
\hline \multirow[t]{2}{*}{ Gender } & Male & $19(50)$ & $4(21.1)$ & $15(78.9)$ & \multirow[t]{2}{*}{0.295} & $11(57.9)$ & $8(42.1)$ & \multirow[t]{2}{*}{0.746} & $7(36.8)$ & $12(63.2)$ & \multirow[t]{2}{*}{0.515} \\
\hline & Female & $19(50)$ & $8(42.1)$ & $11(57.9)$ & & $9(47.4)$ & $10(52.6)$ & & $10(52.6)$ & $9(47.4)$ & \\
\hline \multirow[t]{5}{*}{ Site } & Scalp & $6(15.8)$ & $2(33.3)$ & 4 (66.7) & \multirow[t]{5}{*}{1} & $2(33.3)$ & 4 (66.7) & \multirow[t]{5}{*}{0.502} & $2(33.3)$ & $4(66.7)$ & \multirow[t]{5}{*}{0.256} \\
\hline & Face & $17(44.7)$ & $6(35.3)$ & $11(64.7)$ & & $8(47.1)$ & $9(52.9)$ & & $10(58.8)$ & $7(41.2)$ & \\
\hline & Ear & $5(13.2)$ & $1(20.0)$ & $4(80.0)$ & & $3(60.0)$ & $2(40.0)$ & & $3(60.0)$ & $2(40.0)$ & \\
\hline & Lip & $4(10.5)$ & $1(25.0)$ & $3(75.0)$ & & $2(50.0)$ & $2(50.0)$ & & $0(0)$ & $4(100.0)$ & \\
\hline & Acral & $6(15.8)$ & $2(33.3)$ & $4(66.7)$ & & $5(83.3)$ & $1(16.7)$ & & $2(33.3)$ & $4(66.7)$ & \\
\hline \multirow[t]{2}{*}{ Size } & $<2.0 \mathrm{~cm}$ & $17(44.7)$ & $4(23.5)$ & $13(76.5)$ & \multirow[t]{2}{*}{0.486} & $10(58.8)$ & $7(41.2)$ & \multirow[t]{2}{*}{0.532} & $9(52.9)$ & $8(47.1)$ & \multirow[t]{2}{*}{0.513} \\
\hline & $\geq 2.0 \mathrm{~cm}$ & $21(55.3)$ & $8(38.1)$ & $13(61.9)$ & & $10(47.6)$ & $11(52.4)$ & & $8(38.1)$ & $13(61.9)$ & \\
\hline \multirow[t]{3}{*}{ Differentiation } & Well & $20(52.6)$ & $8(40.0)$ & $12(60.0)$ & \multirow[t]{3}{*}{0.547} & $13(65.0)$ & $7(35.0)$ & \multirow[t]{3}{*}{0.057} & $10(50.0)$ & $10(50.0)$ & \multirow[t]{3}{*}{0.725} \\
\hline & Moderate & $14(36.8)$ & $3(21.4)$ & $11(78.6)$ & & $7(50.0)$ & $7(50.0)$ & & $6(42.9)$ & $8(57.1)$ & \\
\hline & Poorly & $4(10.5)$ & $1(25.0)$ & $3(75.0)$ & & $0(0)$ & $4(100)$ & & $1(25.0)$ & $3(75.0)$ & \\
\hline
\end{tabular}


A

$\begin{array}{ll}\text { (i) } \mathrm{HSC}-1 & \text { (ii) } \mathrm{HSC}-1\end{array}$

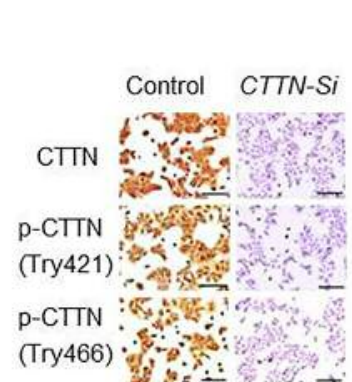

B

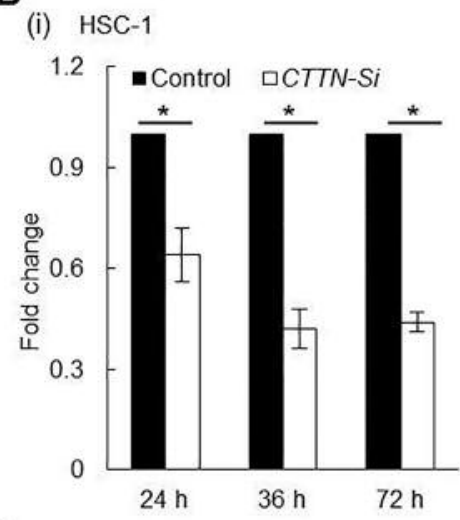

C
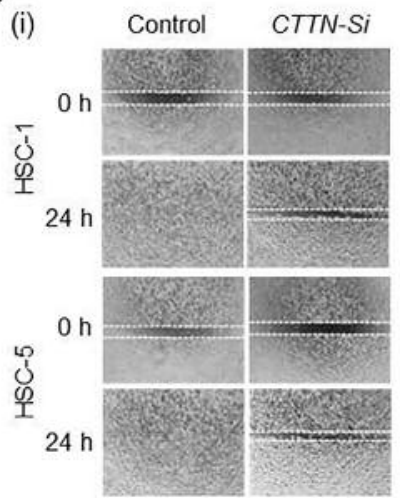

(ii)

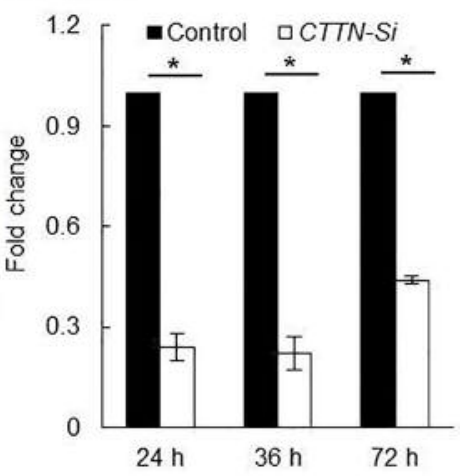

(iii) HSC-5

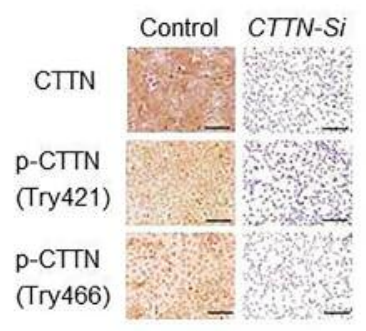

(ii) $\mathrm{HSC}-1$
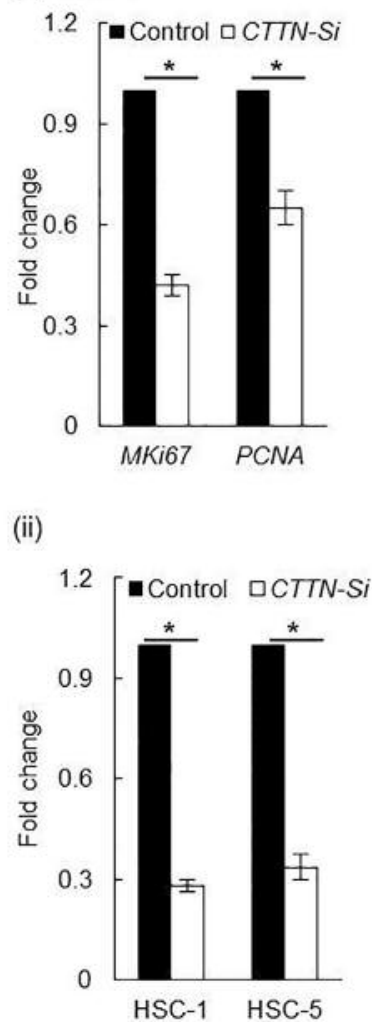

(iii) HSC-5

(iii) (iv) $\mathrm{HSC}-5$

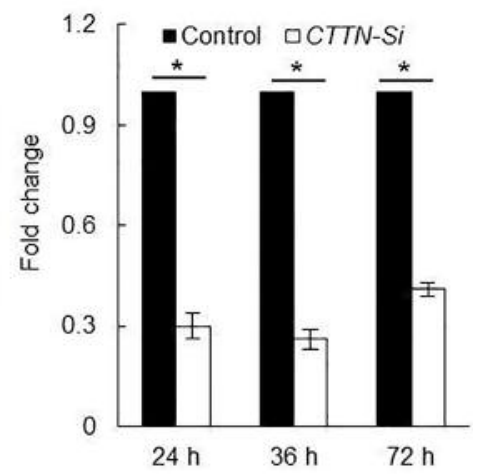

(iv) $\mathrm{HSC}-5$
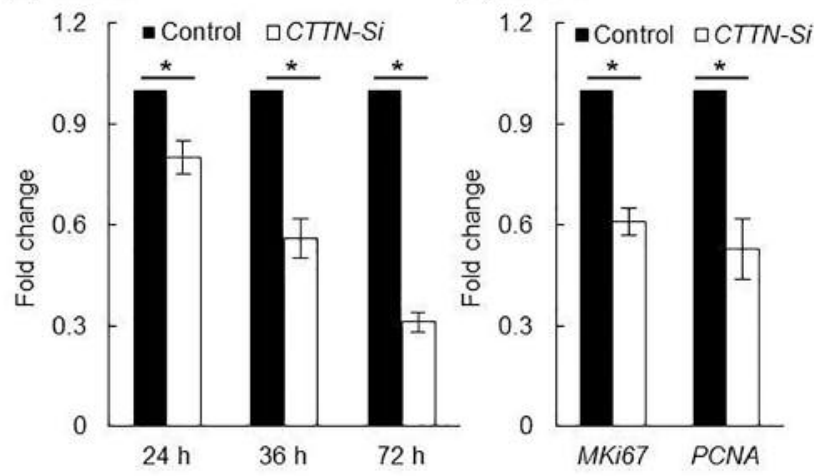

(iv)

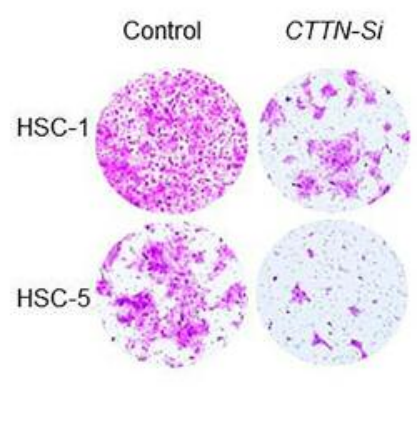

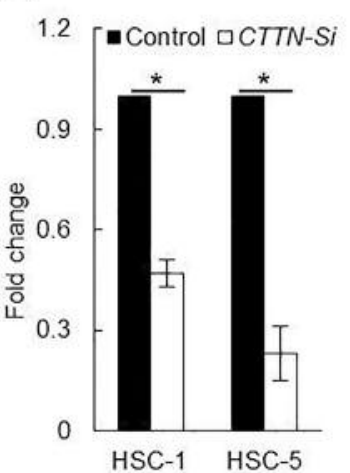

Figure 3. Knockdown of CTTN expression by CTTN-siRNA transfection in CSCC cell lines. A: Both protein (I and iii) and mRNA (ii and iv) expression of CTTN were decreased by CTTN-siRNA transfection. B: Proliferation ability was significantly decreased in CTTN-siRNA transfected HSC-1(i) and HSC-5(iii) cell lines compared to the scrambled control. Supportively, both Ki-67 (MKI-67) and proliferating cell nuclear antigen (PCNA) mRNA expression were significantly decreased in CTTN-siRNA transfected HSC-1(ii) and HSC-5(iv) cell lines compared to the scrambled control. C: Both cell motility ( $i$ and ii) and invasion ability (iii and iv) of the cell lines were significantly reduced after CTTN-siRNA transfection relative to the scrambled control $\left({ }^{*} p<0.001\right)$.

In the present study, a strong CTTN expression was found in CSCC tissue samples, but strong immunoreactivity to CTTN was also frequently observed in normal skin tissue samples, and the difference was not significant. Moreover, in our cohort of CSCC, no significant association was found between CTTN expression and clinicopathological parameters of patients. Some previous studies have reported the absence of CTTN expression in benign tissues, in contrast to the results of this study $(22,25)$, while other studies have also found CTTN expression in normal tissues (18-20). Furthermore, some 
investigators have shown increased CTTN expression in benign tumor tissues compared to in malignant ones (42). The CTTN expression levels in tissues may largely depend on the tissue type in question.

Recent findings indicate that Src-mediated p-CTTN overexpression is more important for the migration ability of cells than CTTN overexpression, there being no demonstrably significant influence on migration ability of cells after transfection of mutant type CTTN (Try421/466/482 mutation) $(36,38)$. Moreover, decreased cell migration ability has been observed after blocking tyrosine phosphorylation of CTTN (33). Increased cell motility plays a critical role in various cell pathological processes including metastasis and recurrence. Some investigators have noticed overexpression of CTTN in malignant tumors, and an association between CTTN phosphorylation and increased cell motility, as well as metastasis $(6,15)$. In this study, p-CTTN expression was detected using the phospho-specific antibodies anti-pTyr421- and anti-pTyr466CTTN, and the results showed that the expression of both was significantly increased in CSCC tissue samples relative to normal skin tissues. Moreover, a significant association was found between CTTN phosphorylation and recurrence-free survival in CSCC patients. These findings indicate a crucial role of p-CTTN expression in CSCC progression.

The molecular mechanisms related to p-CTTN functions remain largely unknown. As a F-actin related protein, CTTN is known to cross-link F-actin into meshwork in vitro. Tyrosine phosphorylation is known to inhibit the ability of CTTN to cross-link F-actin, but it remains controversial whether it affects the ability of CTTN to crosslink actin filaments (43-45). Investigators have shown that CTTN tyrosine phosphorylation controls cell functions by establishing binding sites for effectors such as Nck and Src family kinase (46). Further study is needed to clarify the precise mechanism of p-CTTN function in CSCC.

In summary, CTTN knockdown strongly influenced the biological behavior of CSCC cell lines. Moreover, p-CTTN expression was significantly increased in CSCC tissues relative to normal skin samples, as well as being significantly associated with recurrence-free survival of CSCC patients. CTTN phosphorylation may thus be involved in CSCC pathogenesis. These findings also provide evidence that p-CTTN may serve as a predictive biomarker, as well as therapeutic target in CSCC patients. A larger patient cohort is needed to investigate the clinicopathological implications of both cortactin and p-CTTN for CSCC pathogenesis.

\section{Acknowledgements}

This study was supported by a grant from the Jilin Provincial Health Department Project of china (2014Z094), Jilin Provincial Department of education "thirteen five" science and technology project of china (JJKH20170467KJ), a faculty research grant of Yonsei University College of Medicine of korea (6-2017-0078), and
Basic Science Research Program through the National Research Foundation of Korea funded by the Ministry of Science, ICT and Future Planning (NRF-2017R1C1B1012464).

\section{References}

1 Nehal KS and Bichakjian CK: Update on Keratinocyte Carcinomas. N Engl J Med 379(4): 363-374, 2018.

2 Jambusaria-Pahlajani A, Kanetsky PA, Karia PS, Hwang WT, Gelfand JM, Whalen FM, Elenitsas R, Xu X and Schmults CD: Evaluation of AJCC tumor staging for cutaneous squamous cell carcinoma and a proposed alternative tumor staging system. JAMA Dermatol 149(4): 402-410, 2013.

3 Diepgen TL and Mahler V: The epidemiology of skin cancer. $\mathrm{Br}$ J Dermatol 146(61): 1-6, 2002.

4 Fincham VJ and Frame MC: The catalytic activity of Src is dispensable for translocation to focal adhesions but controls the turnover of these structures during cell motility. EMBO J 17(1): 81-92, 1998.

5 Cary LA, Klinghoffer RA, Sachsenmaier C and Cooper JA: SRC catalytic but not scaffolding function is needed for integrinregulated tyrosine phosphorylation, cell migration, and cell spreading. Mol Cell Biol 22(8): 2427-2440, 2002.

6 Boyer B, Bourgeois Y and Poupon MF: Src kinase contributes to the metastatic spread of carcinoma cells. Oncogene 21(15): 2347-2356, 2002.

7 Huang J, Hamasaki H, Nakamoto T, Honda H, Hirai H, Saito M, Takato T and Sakai R: Differential regulation of cell migration, actin stress fiber organization, and cell transformation by functional domains of Crk-associated substrate. J Biol Chem 277(30): 27265-27272, 2002.

8 LaVallee TM, Prudovsky IA, McMahon GA, Hu X and Maciag T: Activation of the MAP kinase pathway by FGF-1 correlates with cell proliferation induction while activation of the Src pathway correlates with migration. J Cell Biol 141(7): 1647-1658, 1998.

9 Thomas SM and Brugge JS: Cellular functions regulated by Src family kinases. Annu Rev Cell Dev Biol 13: 513-609, 1997.

10 Irby RB, Mao W, Coppola D, Kang J, Loubeau JM, Trudeau W, Karl R, Fujita DJ, Jove R and Yeatman TJ: Activating SRC mutation in a subset of advanced human colon cancers. Nat Genet 21(2): 187-190, 1999.

11 Kramer B, Kneissle M, Birk R, Rotter N and Aderhold C: Tyrosine Kinase Inhibition in HPV-related Squamous Cell Carcinoma Reveals Beneficial Expression of cKIT and Src. Anticancer Res 38(5): 2723-2731, 2018.

$12 \mathrm{Wu} \mathrm{H}$, Reynolds AB, Kanner SB, Vines RR and Parsons JT: Identification and characterization of a novel cytoskeleton-associated pp60src substrate. Mol Cell Biol 11(10): 5113-5124, 1991.

13 Weaver AM, Young ME, Lee WL and Cooper JA: Integration of signals to the Arp2/3 complex. Curr Opin Cell Biol 15(1): 23-30, 2003.

14 Yamaguchi $\mathrm{H}$ and Condeelis $\mathrm{J}$ : Regulation of the actin cytoskeleton in cancer cell migration and invasion. Biochim Biophys Acta 1773(5): 642-652, 2007.

15 Rothschild BL, Shim AH, Ammer AG, Kelley LC, Irby KB, Head JA, Chen L, Varella-Garcia M, Sacks PG, Frederick B, Raben D and Weed SA: Cortactin overexpression regulates actin-related protein $2 / 3$ complex activity, motility, and invasion in carcinomas with chromosome $11 \mathrm{q} 13$ amplification. Cancer Res 66(16): 8017-8025, 2006. 
16 Greer RO Jr., Said S, Shroyer KR, Marileila VG and Weed SA: Overexpression of cyclin D1 and cortactin is primarily independent of gene amplification in salivary gland adenoid cystic carcinoma. Oral Oncol 43(8): 735-741, 2007.

17 Clark ES, Brown B, Whigham AS, Kochaishvili A, Yarbrough WG and Weaver AM: Aggressiveness of HNSCC tumors depends on expression levels of cortactin, a gene in the $11 \mathrm{q} 13$ amplicon. Oncogene 28: 431, 2008.

18 Hofman P, Butori C, Havet K, Hofman V, Selva E, Guevara N, Santini J and Van Obberghen-Schilling E: Prognostic significance of cortactin levels in head and neck squamous cell carcinoma: comparison with epidermal growth factor receptor status. Br J Cancer 98(5): 956-964, 2008.

19 Hirakawa H, Shibata K and Nakayama T: Localization of cortactin is associated with colorectal cancer development. Int J Oncol 35(6): 1271-1276, 2009.

20 Wang GC, Hsieh PS, Hsu HH, Sun GH, Nieh S, Yu CP and Jin JS: Expression of cortactin and survivin in renal cell carcinoma associated with tumor aggressiveness. World J Urol 27(4): 557563,2009

21 Cai JH, Zhao R, Zhu JW, Jin XL, Wan FJ, Liu K, Ji XP, Zhu YB and Zhu ZG: Expression of cortactin correlates with a poor prognosis in patients with stages II-III colorectal adenocarcinoma. J Gastrointest Surg 14(8): 1248-1257, 2010.

22 Yamada S, Yanamoto S, Kawasaki G, Mizuno A and Nemoto TK: Overexpression of cortactin increases invasion potential in oral squamous cell carcinoma. Pathol Oncol Res 16(4): 523-531, 2010.

23 Folio C, Zalacain M, Zandueta C, Ormazabal C, Sierrasesumaga L, San Julian M, de las Rivas J, Toledo G, Lecanda F and PatinoGarcia A: Cortactin (CTTN) overexpression in osteosarcoma correlates with advanced stage and reduced survival. Cancer Biomark 10(1): 35-41, 2011.

24 Matsuo T, Miyata Y, Watanabe S, Ohba K, Hayashi T, Kanda S and Sakai H: Pathologic significance and prognostic value of phosphorylated cortactin expression in patients with sarcomatoid renal cell carcinoma. Urology 78(2): 476.e479-415, 2011.

25 You TK, Kim KM, Noh SJ, Bae JS, Jang KY, Chung MJ, Moon WS, Kang MJ, Lee DG and Park HS: Expressions of E-cadherin, cortactin and MMP-9 in pseudoepitheliomatous hyperplasia and squamous cell carcinoma of the head and neck: Their relationships with clinicopathologic factors and prognostic implication. Korean J Pathol 46(4): 331-340, 2012.

26 Wang L, Zhao K, Ren B, Zhu M, Zhang C, Zhao P, Zhou H, Chen L, Yu S and Yang X: Expression of cortactin in human gliomas and its effect on migration and invasion of glioma cells. Oncol Rep 34(4): 1815-1824, 2015.

27 Yuan BZ, Zhou X, Zimonjic DB, Durkin ME and Popescu NC: Amplification and overexpression of the EMS 1 oncogene, a possible prognostic marker, in human hepatocellular carcinoma. J Mol Diagn 5(1): 48-53, 2003.

28 Kapus A, Di Ciano C, Sun J, Zhan X, Kim L, Wong TW and Rotstein OD: Cell volume-dependent phosphorylation of proteins of the cortical cytoskeleton and cell-cell contact sites. The role of Fyn and FER kinases. J Biol Chem 275(41): 32289-32298, 2000.

29 Crostella L, Lidder S, Williams R and Skouteris GG: Hepatocyte Growth Factor/scatter factor-induces phosphorylation of cortactin in A431 cells in a Src kinase-independent manner. Oncogene 20(28): 3735-3745, 2001.

30 Huang C, Liu J, Haudenschild CC and Zhan X: The role of tyrosine phosphorylation of cortactin in the locomotion of endothelial cells. J Biol Chem 273(40): 25770-25776, 1998.
31 Vuori K and Ruoslahti E: Tyrosine phosphorylation of p130Cas and cortactin accompanies integrin-mediated cell adhesion to extracellular matrix. J Biol Chem 270(38): 22259-22262, 1995.

32 Wang W, Chen L, Ding Y, Jin J and Liao K: Centrosome separation driven by actin-microfilaments during mitosis is mediated by centrosome-associated tyrosine-phosphorylated cortactin. J Cell Sci 121(Pt 8): 1334-1343, 2008.

33 Wang W, Liu Y and Liao K: Tyrosine phosphorylation of cortactin by the FAK-Src complex at focal adhesions regulates cell motility. BMC Cell Biol 12: 49, 2011.

34 Ammer AG and Weed SA: Cortactin branches out: roles in regulating protrusive actin dynamics. Cell Motil Cytoskeleton 65(9): 687-707, 2008.

35 Kruchten AE, Krueger EW, Wang Y and McNiven MA: Distinct phospho-forms of cortactin differentially regulate actin polymerization and focal adhesions. Am J Physiol Cell Physiol 295(5): C1113-1122, 2008.

36 Jia L, Uekita T and Sakai R: Hyperphosphorylated cortactin in cancer cells plays an inhibitory role in cell motility. Mol Cancer Res 6(4): 654-662, 2008.

37 Li Y, Tondravi M, Liu J, Smith E, Haudenschild CC, Kaczmarek $\mathrm{M}$ and Zhan $\mathrm{X}$ : Cortactin potentiates bone metastasis of breast cancer cells. Cancer Res 61(18): 6906-6911, 2001.

38 Lai FP, Szczodrak M, Oelkers JM, Ladwein M, Acconcia F, Benesch S, Auinger S, Faix J, Small JV, Polo S, Stradal TE and Rottner K: Cortactin promotes migration and platelet-derived growth factor-induced actin reorganization by signaling to RhoGTPases. Mol Biol Cell 20(14): 3209-3223, 2009.

39 Zhang X, Zheng Z, Shin YK, Kim KY, Rha SY, Noh SH, Chung $\mathrm{HC}$ and Jeung HC: Angiogenic factor thymidine phosphorylase associates with angiogenesis and lymphangiogenesis in the intestinal-type gastric cancer. Pathology 46(4): 316-324, 2014.

40 Wang X, Cao W, Mo M, Wang W, Wu H and Wang J: VEGF and cortactin expression are independent predictors of tumor recurrence following curative resection of gastric cancer. J Surg Oncol 102(4): 325-330, 2010.

41 Sheen-Chen SM, Huang CY, Liu YY, Huang CC and Tang RP: Cortactin in breast cancer: analysis with tissue microarray. Anticancer Res 31(1): 293-297, 2011.

42 Fujii M, Honma M, Takahashi H, Ishida-Yamamoto A and Iizuka $\mathrm{H}$ : The nuclear factor kappa B p50 subunit and cortactin as markers to distinguish between keratoacanthoma and well-differentiated squamous cell carcinoma. Clin Exp Dermatol 36(7): 788-792, 2011.

43 Huang C, Ni Y, Wang T, Gao Y, Haudenschild CC and Zhan X: Down-regulation of the filamentous actin cross-linking activity of cortactin by Src-mediated tyrosine phosphorylation. J Biol Chem 272(21): 13911-13915, 1997.

44 Weed SA and Parsons JT: Cortactin: coupling membrane dynamics to cortical actin assembly. Oncogene 20(44): 6418-6434, 2001.

45 Weaver AM, Karginov AV, Kinley AW, Weed SA, Li Y, Parsons JT and Cooper JA: Cortactin promotes and stabilizes Arp2/3-induced actin filament network formation. Curr Biol 11(5): 370-374, 2001.

46 Okamura $\mathrm{H}$ and Resh MD: p80/85 cortactin associates with the Src SH2 domain and colocalizes with v-Src in transformed cells. J Biol Chem 270(44): 26613-26618, 1995.

Received November 6, 2018

Revised November 21, 2018 Accepted November 22, 2018 